\title{
Effect of Growth Media and Incubation Time on the Culturability of Soil Bacteria
}

\author{
C.B. Chikere ${ }^{1,}$ And U. Udochukwu ${ }^{1,2}$ \\ ${ }^{1}$ Department Of Microbiology, Faculty Of Life Science University Of Port Harcourt, River State, Nigeria \\ ${ }^{2}$ Department of Bioscience, College of Natural and Applied Sciences, Salem University-lokoja, Kogi State, \\ Nigeria
}

\begin{abstract}
The effect of growth medium and incubation time were investigated by determining the number of colonies that were visible on triplicate plates of three different media on daily intervals. The viable counts were significantly different between the three different media even after the first day and this continued for seven days. Colony counts on the three media reached their maximum on the third day of incubation. The use of Nutrient agar (NA) and Plate count agar (PCA) resulted in increasing counts with increasing incubation time respectively. Counts obtained from the Nutrient agar were higher than that of Plate count agar followed by the soil extract agar (SEA) which had the lowest count and a longer bacteria lag phase due to the low nutrient content in the soil extract agar. The Plate count agar formed more distinct colonies than the Nutrient agar and Soil extract agar. During the incubation period, colonies appeared on the Nutrient agar even on the seventh day. These characteristics of the Nutrient agar to support a higher number of colonies for a long period of time could be attributed to its nutrient composition. The colony counts upon incubation for seven days ranged from a mean of $3.0 \times 10^{5} \mathrm{cfu} / \mathrm{g}$ on Soil extract agar, $6.1 \times 10^{5} \mathrm{cfu} / \mathrm{g}$ on Plate count agar and $7.6 \times 10^{5} \mathrm{cfu} / \mathrm{g}$ on Nutrient agar for example A which was a cultivated loamy soil and $1.3 \times 10^{5} \mathrm{cfu} / \mathrm{g}$ also on Soil extract agar, $3.9 \times 10^{5} \mathrm{cfu} / \mathrm{g}$ on Plate agar and 5.6x10 5 cfu/g Nutrient agar for soil sample B which was a non-cultivated sandy soil. Longer incubation time increased colony count on the different growth media because it was so obvious on the Soil extract agar. No visible colonies were observed from the first to the third day on the Soil extract agar, visible colonies appeared on the fourth day of incubation. Also in the other growth media, there was an increase in colony count on the third day upon incubation.
\end{abstract}

Key Words; Growth Medium, Incubation Time, Culturability and Soil Bacteria.

\section{Introduction}

It was observed that there are some groups of bacteria that are rarely isolated between 24 to 48 hours. Therefore this experiment was carried out to know the factors that could play important roles in the isolation of the rarely isolated groups of bacteria. Special growth media and extended incubation time were suggested by[3] and [2] to be among the factors that could support the isolation of this group of bacteria. Media like the soil extract ager which does not have many nutrients to support the growth of bacteria for a long time. It was observed by [3] that due to the low nutrient content in the soil extract agar, colonies appeared on the soil extract agar after some days and disappeared also within some days. Basically soil is a living heterogeneous system with characteristics physical, biological and chemical properties. A number of features characterized this region of the earth's crust. Agriculturally, the soil is the region supporting plant and they obtain their mechanical support and many plants nutrients. Chemically, the soil contains a multitude of organic substances not found in the underlying strata. For the microbiologist, the soil environment is unique in several ways: it contacts a vast population of Bacteria, Actinomycetes, Fungi, Algae, and Protozoa; it is one of the most dynamic sites of biological interaction in nature [1]. In more advanced research, [6] used the 16s RNA isolate these groups of rarely isolated using the polymerase chain reaction machine and the gel electrophoreses.

\section{Materials And Methods}

Two soil samples were obtained from department of Soil science, faculty of Agriculture University of Port-Harcourt Rivers State Nigeria. Soil sample A was a cultivated loamy soil and sample B was non-cultivated sandy soil. An accurately weighed sample of freshly sieved soil (approximately 1g) was dispersed in $9 \mathrm{ml}$ of sterile distilled water. These $10^{-1}$ diluted aliquots were serially diluted to $10^{-2}, 10^{-3}, 10^{-4}, 10^{-5}$ and $10^{-6}$ and $0.1 \mathrm{ml}$ of each of the dilution was used to inoculate each of 3 replicate plates by the use of a sterile syringe at each dilution level to constitute a counting set of 9 plates. Inocula were spread over the surface of the plates by the use of sterile glass rods. Three counting sets were prepared on each medium (Nutrient agar, Plate count agar and Soil extract agar) for each soil sample. All 72 plates were incubated at $37^{\circ} \mathrm{C}$ wrapped in a foil paper for 7 days to avoid contamination. Viable counts are expressed relative to dry weight of soil. Colony formation was 
monitored by examining plates after the first day, second day till the seventh day. Colonies on the three different growth media for the two soil samples were counted and calculated using the colony forming unit formula.

\section{CFU/G $=\quad$ AVERAGE COUNT DILUTION X VOLUMN PLATED (1)}

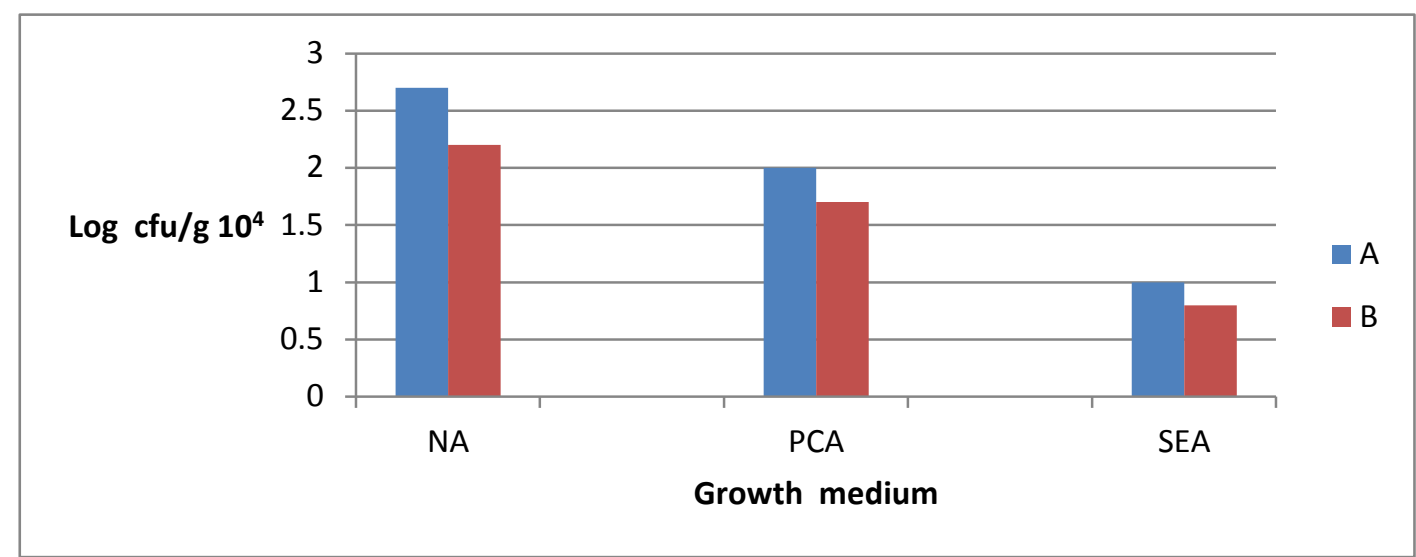

Fig 1.A bar chart representing the relationship of the log cfu/g among the three different growth media between soil sample A (Cultivated loamy soil) and B (Non-cultivated sandy soil).

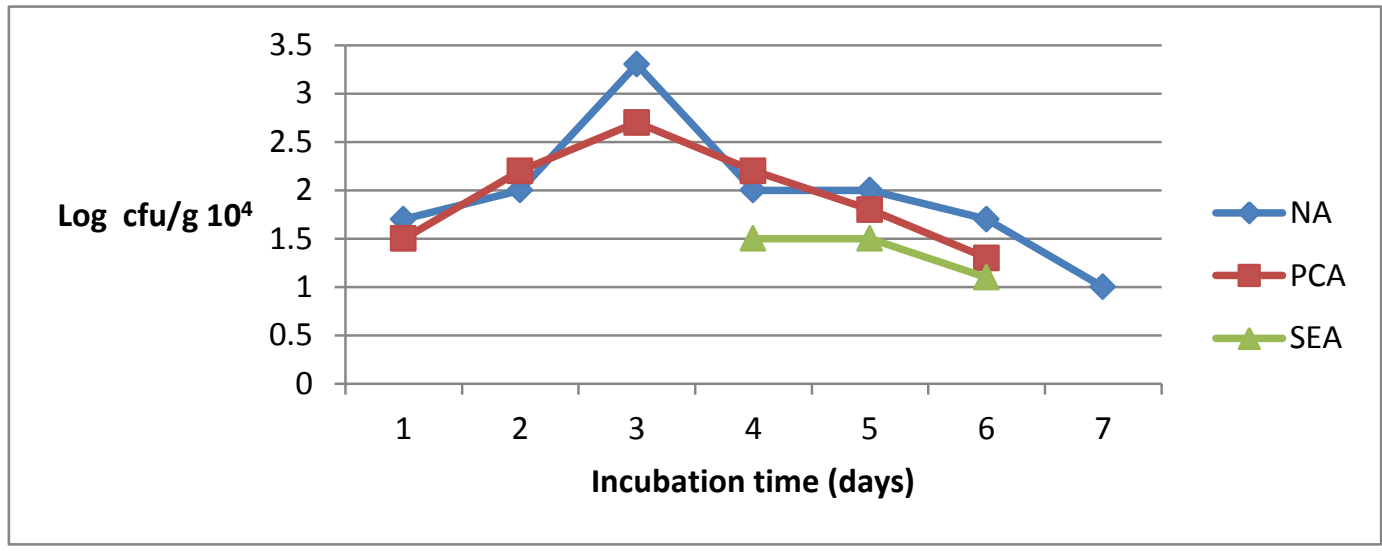

Fig. 2.A graph of log cfu/g against incubation time showing the effect of extended incubation time on the the cultivability of soil bacteria with respect to three different growth media.

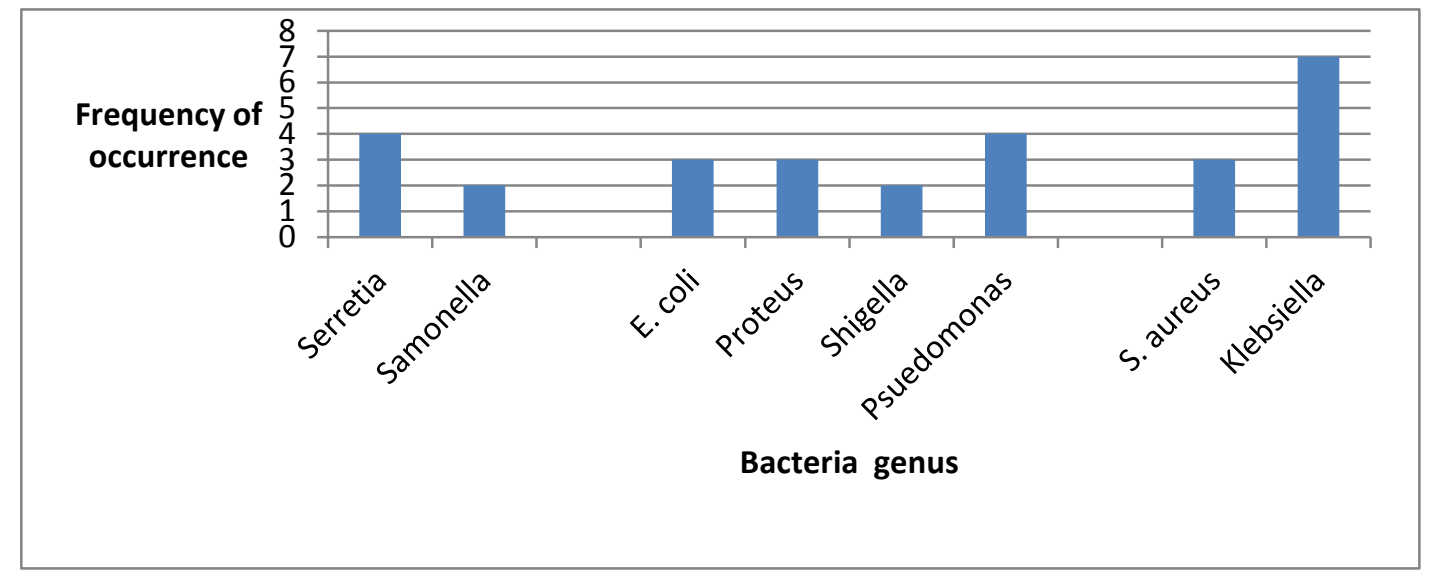

Fig. 3: Frequency of occurrence of probable isolates from the soil sample. 


\section{Results}

The total heterotrophic bacterial count on both soil samples varied significantly. Colony count were higher in the cultivated loamy soil which was the soil sample A, while there was a lower counts on the noncultivated sandy soil which was the soil sample B for the three different growth media in seven days of incubation. The cultivated loamy soil showed mean counts of $5.56 \times 10^{5} \mathrm{cfu} / \mathrm{g}$ while the non-cultivated sandy soil had a mean count of $3.6 \times 10^{5} \mathrm{cfu} / \mathrm{g}$. Nutrient agar had a mean count of $45.5 \%, 36.5 \%$ for Plate count agar $18.0 \%$ for Soil extract agar all for soil sample A. For soil sample B, Nutrient agar had $51.9 \%, 36.1 \%$ for plate count agar and $12.0 \%$ for Soil extract agar.

Fig. 1.As shown above is representing the relationship of $\log \mathrm{cfu} / \mathrm{g}$ among the three different growth media between the two soil samples. Colony count on the Nutrient agar was higher than that of Plate count agar and the Soil extract agar. This could be attributed to the high nutrient composition of the nutrient agar compared to other growth media. Species of Klebsiella were mostly isolated from the Nutrient agar plate followed by species of Pseudomonas, colonies on the Nutrient agar appeared larger and robust with diameter of $0.3 \mathrm{~mm}$ to $4.0 \mathrm{~mm}$ compared to other growth media like Plate count agar which had an average diameter of $0.2 \mathrm{~mm}$ but formed a more district colonies on the plate. Species of Serratia were mostly isolated from the Plate count agar. Generally, the cultivated loamy soil sample (Soil sample A) had higher colony count which is due to the effects of agricultural activities on the soil. If a growth medium has a high nutrient composition, there will also be a corresponding high colony count on that particular growth medium, because of the low nutrient composition of the Soil extract agar; organisms find it difficult to form visible colonies on it. Therefore it took longer time for visible colony formation on the Soil extract agar.

Fig. 2 as shown above shows the relationship between $\log \mathrm{cfu} / \mathrm{g}$ and incubation time of three growth media. Nutrient agar (NA) plate count agar (PCA) and soil extract agar (SEA). Generally, fig 2. Shows the effect of incubation time on the cultivation of soil bacteria. On the first day of incubation, there were visible colony formation on the Nutrient agar and the Plate count agar plates. As incubation time increased, there was also a corresponding increase in colony count. The highest colony count was recorded on the third day. For Soil extract agar plates, there was no visible colony from the first to the third day of incubation. After the third day, visible colonies appeared on the soil extract agar plates. Therefore, increased incubation time increased colony count on the growth medium. Increase incubation time improved the cultivation of soil bacteria.

A total of eight bacteria genus were isolated from the two soil sample used in the study, some were Klebsiella, Staphylococcus, Salmonella, Serratia, shigella, Pseudomonas, Escherichia coli and Proteus. Their percentage of occurrence was calculated and is represented in a bar chart as shown in fig. 3 above.

\section{Conclusion}

Soil contains a great diversity of bacteria genus, with many of the organisms belonging to groups for which no cultivated representatives are known. It has been claimed that plate count methodologies are not suitable for cultivation of soil bacteria and that the number of group without cultivated representatives are somehow non-culturable. By increasing the incubation time as suggested by [6], we should be able to isolate some members of groups that to date have not been grown in pure culture. According to [14] and [13] the use of serial dilution, liquid culture techniques has proved to be effective for isolating numerically significant members of the community in cultivated and non-cultivated soil samples. However, when this techniques was used to cultivate bacteria from the Nutrient agar, Plate count agar and Soil extract agar, the mean viable count obtained were $45.5 \%, 36.5 \%$ and $18.0 \%$ for sample A (cultivated sandy loamy soil) and $51.9 \% .36 .1 \%$ and $12.0 \%$ for sample B (non- cultivated sandy soil)

The effect of growth media and incubation time were investigated in viable counts as described by [5],[9] and [10]. Some media that are traditionally used for soil microbiological studies returned low viable counts and did not result in the isolation of members of rarely isolated groups. Like the Soil extract agar as used by [2] and [5]. Newly developed media in contrast resulted in high viable counts and in the isolation of members of rarely isolated group regardless of the inoculums size [8]. Increased incubation time of up to 3 months allowed the development of visible colonies of members of rarely isolated groups which took longer time to form visible colonies than that of members of commonly isolated groups. According to[4],[7] and [12] who used these media and extended incubation time observed isolates of many members of the Phyla. Acidobacteria (subdivision 1, 2, 3 and 4), Gemmatimonadetes, Chloroflexi and Planctomycetes.

In this investigation, isolates were identified by using various biochemical analysis and morphological characteristics. But these isolates can also be identified by molecular methods using the 16s RNA sequence as used by [11]. This method is useful in identification of various microbial species present in the soil samples. The systems investigated were a cultivated sandy loamy soil and a non-cultivated sand oil sample. The success in this investigation was attributed to the method used. The successful isolation of members of bacteria genus that are widely distributed and common in soil worldwide seems to be a result of using appropriate media and 
extended incubation time. This investigation demonstrates the significance of medium choice and incubation time on the successful isolation of soil bacteria.

\section{References:}

[1]. Bollmann, A., Palumbo, A. V., Lewis, K., Epstein, S. S.; (2010): Isolation And Physiology of Bacteria from Contaminated Subsurface Sediments. Appl. Environ. Microbial 76:7413-7419.

[2]. Bollmann, A., Lewis, K., Epstein, S S.; (2007): Incubation of Environmental Samples In A Diffusion Chamber Increases. The Diversity Of Recovered Isolates. Appl. Environ. Microbial. 73:6386-6390.

[3]. Buckley, D. H., Huangyutitham, V., Nelson, T. A., Rumberger, A.; (2006): Diversity of Planctomycetes in Soil In Relation To Soil History and Environmental Heterogeneity. Appl. Environ. Microbial. 72:4522-4531.

[4]. Eichorst, S. A., Brezenak, J. A., Schmidt, T. M.; (2007): Isolation and Characterization Of Soil Bacteria That Define Terriglobus Gen. Nov., In The PhyiumAcidobateria. Appl. Environ. Microbial. 73: 2708-2717.

[5]. Ferrai, B. C., Gillings, M. R.; (2009) : Cultivation of Fastidious Bacteria by Viability Staining and micromanipulation in a soil substrate membrane system. Appl. Environ. Microbiiol. 75: 33352-3354.

[6]. Janssan, P. H.; (2006) : Identifying the Dominant Soil Bacterial Taxa in Libraries of 16s RNA And16s RNA Genes. Appl. Environ. Microbial. 72: 1719-1728.

[7]. Kielak, A.M.J., Van Veen, A., Kowalchuk, G.A.; (2010): Comparative Analysis of $\quad$ Bacteria Genomic Fragments from Terrestrial and AcquaticMetagenomic Libraries, With Emphasis on Acidobacteria Subdivision 6. Appl. Environ. Microbiol. 76: 6769-6777.

[8]. Osborne, C. A., Peoples, M .B., Janssen, P .H.; (2010) : Detection of a Reproducible, Single Member Shift in Soil Bacterial Communities Exposed To Low Level of Hydogen. AppI. Environ.Microbiol.76: 1471-1479.

[9]. Rasmussen I. D., Zawadsky, C., Binnerup, S .J.,Oregaard, G., Soresen, S. J., Kroer. N.; (2008) : Cultivation of hard - to - culture subsurface mercury - resistant Bacteria and discovery of new a gene sequences. Appl. Environ. Microbial 74: 3795-3803

[10]. Shimiomura, Y .R., Kawai, F., Kimbara, K.; (2006) : Method for Assessment Of Viability and Morphological Changes of Bacteria in the Early Stage of Colony Formation on a Simulated Natural Environment. Appl. Environ. Microbial. 72: 5037-5042.

[11]. Sangwan, P., Kovac, S., Davis, K. E. R., Sait, M., Janssen, P .H.; (2005)........Detection And Cultivation of Soil Verrucomicrobia. Appl. Environ. Microbial..71:8402-8410.

[12]. Yasir, M., Song, G .C.Jeon, C. O., Chung, Y. R.; (2010) :Sphingosinicella Vermicomposit Sp. Nov., Isolated from Vermicomposit, And Emended Description of the Genus Sphingosinicella. Int. J. Syst. Evol. Microbial. 60:580-584.

[13]. Zhang, J. Y., Liu, X. Y.; (2010) :Sphingomonas changbaiensis. Nov., Isolated From Forest Soil. Int. J. Syst. Evol. Microbial.60: 790- 795.

[14]. Zhang, J. Y., Lius, X. Y., Liu, S. J.; (2010):Agrococcusterreus and Micrococcus terreus . Nov. Isolated from Forest Soil. Int. J. Systl. Microbial.60:1897 - 1903. 